\title{
ACHIEVING MILLENNIUM DEVELOPMENT GOALS FOR CAN WE ACHIEVE THE TARGETS?
}

\author{
Hewageegana, N.S.R*
}

In 2000, 189 heads of state signed the Millennium Declaration, committing to achieve eight development goals for their countries and Sri Lanka is one of the signatories of this declaration. Of these 8 goals, 3 were exclusively related with the health sector and they are 4, 5 and 6.The target for MDG 4 (Reduce Child Mortality) was to reduce the under- 5 mortality rate by two-thirds between 1990 and 2015, and the target for MDG 5 (Improve Maternal Health) was to reduce the maternal mortality ratio by three-quarters during the same period. Target for MDG 6 (Combat HIV/AIDS. Malaria and other diseases) was to halt and reverse the incidence of Malaria, Tuberculosis and HIV/AIDS by 2015 .

According to the 2008/09 United National Development Program Country Report, Sri Lanka is on track for achieving health related MDG's by 2015 except for Tuberculosis. But there are regional disparities of achieving these targets within Sri Lanka and with the culmination north and east conflict after 30 years and with the non-extension of development to certain parts of Sri Lanka, there are numerous challenges of serving these less privileged communities to achieve these targets.

In relation to MDG 4, major proportion of Under 5 year mortality is comprised of deaths in neonatal period and these were mainly due to pre-term births and birth asphyxia. Thus it is imperative to have more specialized care units and human resources for neonatal care, which invariably is a costly exercise. Yet it is of paramount importance to ensure the sustainability of MDG -4 and achieving the equity of resource distribution towards neonatal care is a major challenge.. In subsequent life, communicable diseases such as diarrhoeal diseases, pneumonia and measles achieve importance, and with the accomplishment of immunization targets and advancement of water and sanitation levels along with improved maternal education, this would become more achievable and sustainable.

In a current context, medical causes complicating pregnancy, septic abortion and suicides are the main causes of maternal mortality. Nevertheless, haemorrhage of pregnancy and pregnancy Induced Hypertension cannot be ignored when considering MDG 5, as these are linked with access to quality ante-natal, natal and post natal care and maternal under-nutrition. Again the regional disparities of specialized obstetric care including blood transfusion facilities are of prime importance and these should be equitably and adequately distributed to achieve sustainability. Additionally, contraceptive usage as measured by the contraceptive prevalence rate is also a major contributory factor when considering the contribution of septic abortions towards maternal morbidity and mortality. With the recent alterations of policies and attitudes towards contraception and with more married females being guided towards illegal abortions due to unmet need, there is an immense challenge for the health sector to curb this menace with more coordinated and novel approaches.

Although Sri Lanka is a low prevalence country considering HIV/AIDS, there are many vulnerable factors for the spreading of infection ranging from biological to behavioural and socio-economic factors. These make the sustainability of the low prevalent state very vulnerable. With the end of North and East Conflict and with fewer preventive opportunities along with more options for spreading such as resettlement of displaced people, Malaria could be another major challenge in the future. Tuberculosis continues to be major burden to the country and it is unlikely to meet with the MDG targets by 2015 . The emergence of Multi Drug Resistant Tuberculosis poses a further challenge.

Thus equitable distribution of specialized care and resources to minimize regional disparities especially in liberated regions of Northern and Eastern provinces and innovative thinking in the midst of turbulent policies are essential prerequisites to achieve and sustain millennium development goals for Sri Lanka, which will ensure our expectations of making our motherland the "Miracle of Asia”. 